\title{
WHITHER LIBRARY EDUCATION?
}

\author{
keynote speech at the joint EUCLID/ALISE conference \\ "Coping with continual change—change management in SLIS"
}

Fachbochschule Potsdam

Potsdam, Germany, July 31'st, 2003

Abstract. Delineates the problems facing library education, particularly in the United States. Proposes changes in curricula, faculty, and diversity in library education. Calls for a restructuring of library education for the $21^{\text {st }}$ century.

I long ago came to the conclusion that there are two types of paper that are very difficult to write. The first are those on a subject on which one has little to say. The task of spinning that little out to a talk of a decent length is almost intolerable. The second are those on a subject on which one has a great deal to say. The task of paring a book's worth of material into a paper at a conference is even more daunting. I fear this paper is one of the latter sort and each paragraph must bear the weight of a chapter and the paper itself lead to conclusions that deserve a book's length of justification.

I believe there is a crisis in library education, varying in severity from country to country, but omnipresent nonetheless. I also believe we need a new (or resuscitated) model of library education that will meet the demands of libraries and librarianship in the years to come. You will note that I use the term "library education" and not LIS, for reasons that will soon become 
apparent. I am a librarian and an employer of librarians and my view of the crisis is shaped by my experiences in the latter capacity. I can only speak of library education outside the USA as a distant observer and reader of professional journals and books, and will confine any specifics, therefore, to the United States.

Let me begin by looking at the wider context. There are many aspects to that context and the following are simply the most obvious components (in no special order).

The average age of librarians in the US is high and rising. A large number of those librarians will be retiring or carried out feet first in the next 5-10 years. It is vital that enthusiastic, educated librarians replace them.

- At last count there were more than 117,000 libraries of all kinds in the USA. These included more than 9,000 public libraries and public library systems, nearly 4,000 academic libraries, more than 90,000 school libraries, more than 9,000 special libraries, and nearly 2,000 government and military libraries. ${ }^{i}$

There are 50 ALA-accredited library schools in the US and 7 in Canada. There are a far larger number of accredited programmes and credentialing agencies for school librarians. 
The state of California (with a population several millions larger) has 2 accredited library schools to Canada's 7 - the same as Denton, TX, a town of fewer than 400,000 people. This is only the most dramatic example of the inequity of distribution and the paucity of number of US library schools.

What we used to call library schools have, perforce, become hosts to information science and information studies faculty and curricula. These disciplines (if they exist at all) are, at best, peripheral to library work and, at worst, inimical to it. ${ }^{\text {ii }}$

Studies have shown that there is a growing gender divide in LIS schools between "information science" oriented male teachers and library course oriented females teachers. ${ }^{\text {iii }}$ Further, that as female library oriented teachers retire they are likely to be replaced by "information science" oriented teachers.

Some prestigious research universities ${ }^{\mathrm{iv}}$ in the USA have given up in LIS education. This has led to a diminution of the research (in terms of quality if not quantity) into library topics.

Many of the topics regarded as central to a library education (cataloguing, reference, collection development, etc.) by would-be 
employers are no longer central to, or even required by, today's LIS curricula.

The American Library Association's approach to accreditation of LIS schools in the US and Canada is centered on the vision and mission of the individual schools rather than on norms such as core curricula, national examinations, etc. This means that the prospective employer has no idea what the holder of a master's degree knows or has learned.

There is considerable confusion in the profession of librarianship as a whole on two crucial issues. The first is the inability to distinguish between education and training in librarianship. Education is the realm of the library schools, but training is the duty of the employing institution. The second is a lack of consensus on the nature of librarianship. ALA's recent struggles to formulate agreed statements on the core values and required competencies of librarianship illustrate this confusion. $^{v}$ Professions are defined by their ability to control education for that profession and agreement on the basic areas of study required for such an education. My submission is that our profession is perilously close to losing control of both.

Many library educators (whether trained as librarians or information scientist, but especially the latter) have lost faith in, and regard for the traditional mission, policies, programs, and value of libraries and are 
more interested in research in their areas of interest (outside librarianship) or in equipping their students to take jobs in other areas of work.

The seductions of modern communications technology have led many library educators to concentrate on that technology and dismiss anything about libraries that is not amenable to a technological solution. This is a world in which fantastic schemes for virtual libraries and the worlds' recorded knowledge available on the Internet and the Web are presented as if they were real components of the short-term future, despite the fact that they fly in the face of history and facts. We do not need these urban myths to be propagated in LIS schools or, worse, to be presented as facts to a new generation of librarians.

* The gap between what is being taught in many LIS schools and what is being practiced in most libraries is wide and widening. Equally, the increasing different life experiences of LIS educators and library practitioners contribute to mutual misunderstanding. Just to take a few examples, the real life quotidian library struggles:

- with incorporating technology into library service while maintaining existing services; 
- striving to preserve the human record and make sense out of the howling wilderness of the Web;

- and teaching library skills to increasingly a-literate library users are not addressed in a serious manner (or at all) by LIS educators. That gap between theory and practice, each operating on different premises, is the most serious argument for complete reform of library education. There is a dearth of research in US LIS schools that is dedicated to the real needs of real libraries. This is the result both of the divorce between information science oriented faculty and practicing librarians and of the fact that LIS schools in the US tend to be part of large universities that value (and reward) pure research over applied research. This has led to a gap in the library journal literature between arid and inaccessible reports of pure research and naïve "how we did it good" reports.

This has been a litany of the negative aspects of the library education crisis, but it should not be taken as a blanket indictment of all library educators or even of all LIS schools. However, it is also an outline of a tangled skein of problems that must be solved if we are to have a sufficient number of new librarians to staff the libraries and library services of the decades to come. You will note that I do not mention those who, having achieved an LIS degree, choose to work in areas other than libraries. This is not because I disapprove 
of that choice or even think that LIS schools should not educate such people. I look upon them with benevolence, much as I look upon future doctors and nurses with benevolence, but their needs and careers are not central to my concerns. In particular, I believe that the education of future librarians should be the prime concern of LIS schools or, rather, that the ALA should not accredit those schools in which the education of future librarians is subservient to other considerations.

The solution to the library education crisis must have many elements. I will suggest here a number of areas in which change, in many cases radical change, is needed and wrap them up in an overall proposal in conclusion.

Curricula. The nub of the question of library education, as it is with any level of education in any subject, is what is taught. It is instructive to look at what goes on in libraries and the areas in which a would-be librarian should be knowledgeable, if we are to devise a core curriculum that would apply to all schools.

* Collection development and acquisitions: Librarians select, acquire, and give access to carriers of recorded knowledge and information in all formats and must be knowledgeable about the processes and broad policies of this activity.

- Cataloguing: Librarians organize those carriers and arrange access to them by creating catalogues, indexes, and other controlled guides to those 
carriers and their contents. There are two levels of education in cataloguing. The first is applicable to all would be librarians in that cataloguing teaches students to think like librarians and provides the intellectual structure that underlies all professional library work. The second, more intensive level is for people who wish to apply knowledge of cataloguing directly.

Reference and library instruction: Librarians provide assistance and instruction on how to find, select, and evaluate recorded knowledge and information in all forms, and how to assess the value of what is retrieved.

* Circulation, maintenance, preservation, etc.: Libraries arrange access to physical carriers, maintain the collections of such carriers, and preserve recorded knowledge and information in all formats.

Systems: Systems librarians install, modify, maintain, and, in increasingly rare instances, create computer systems to assist in and improve all the foregoing activities. Maintaining the library's Web presence is an increasingly important systems responsibility.

Management: Librarians manage and administer the libraries in which these activities take place. This includes all library services, staff, and the environment in which the library exists. 
Types of library: All these activities take place in one form or another in every library, but the relative importance and nature of each vary greatly depending on the type of library. Librarians need an education in those differences.

Any balanced analysis of the preceding core activities will recognize that each has a quantum of professional activity and each an, in almost all cases, a larger quantum of para-professional and non-professional activity. The curricula of library schools should, of course, focus on the former but not ignore the question of the management of the latter. Obvious examples are original as opposed to copy cataloguing; reference work as opposed to work at an information desk or help center; and library systems management as opposed to technical tasks such as the maintenance of Web pages.

In addition to these core and common activities in all libraries, there are activities that are special to certain types of library. Examples are story-telling and children's literature in children's libraries; information retrieval systems in special libraries; and conservation in rare book and media libraries.

Faculty. The most important part of the resolution of the library education problem lies in the nature and type of the faculty members in LIS schools. Many US LIS schools are in research universities and their faculty members tend to conform to the norms and ideals of those institutions. If you study the evolution of library education, you will see a long march away from vocational 
education of the practical type through a period of, in my view, a worthwhile amalgam of professional and intellectual education, to the present day in which abstract theory, especially in areas only peripherally related to librarianship, dominates. Similarly, the early library schools produced little in the way of research, the schools of the period from, roughly, the 1930s to the 1970s produced a considerable amount of applied research of use to libraries, and the LIS schools of today produce a quantity of pure research that is either in peripheral areas or in areas unrelated to library work. Though these changes have been driven, to some extent, by changes in the culture of academia, they have to a greater extent been driven by changes in who the people who teach in LIS schools are. Many contemporary LIS faculty members have no training in librarianship and/or little or no experience working in libraries.

I recently looked a list of the faculty teaching in one of the USA's longest established and prestigious LIS schools. The list of the courses taught and research interests of those faculty include a number of library topicsschool libraries, subject access, collection management, descriptive bibliography, etc.—but these are heavily outweighed by topics such as (chosen from many at random) user modeling, information visualization, humancomputer interaction, business taxonomies, strategic intelligence, social and organizational informatics, computational linguistics, electronic commerce, and computer programming for information management. It is not without 
significance that this school has a large number of adjunct faculty, almost all practicing librarians, who teach courses in, for example, law libraries, collection development, library automation, Slavic librarianship, music librarianship, bibliographic instruction, and story-telling. I believe this pattern of core faculty occupied almost exclusively, in teaching and doing research in information science areas and leaving the bulk of library education to adjunct professors is not at all uncommon in the US. We can readily see that both the culture and individual interests of LIS faculty are, increasingly, marginalizing education in librarianship in favor of information science and other computer related interests and courses. This may or may not be a bad thing for those schools but it is, undoubtedly, a bad thing for librarianship and its future.

Accreditation. There are two basic models by which a profession can seek to control education for its would-be members. The first is based on a consensus on the core requirements for a person to be educated in that profession leading to agreements on the basic curriculum to be taught in the schools that are certified to educate future members of that profession. For example, the American Medical Association states:

The American Medical Association and the Association of American Medical Colleges ( $\underline{\text { AAMC) }}$ ) are joint sponsors of the Liaison Committee on Medical Education ( $\underline{\mathrm{LCME}}$ ), which accredits medical school programs leading to the MD degree. Since 1942, the LCME has been the nationally recognized agency for the accreditation of US and Canadian medical programs.

Accreditation signifies that national standards [my emphasis] for structure, function, 
and performance are met by a medical school's education program leading to the MD degree. ${ }^{\text {vi }}$

The second approach is to accredit each school based not on national standards but on that school's own vision and mission and to judge them on the latter. If an LIS school seeking ALA accreditation chooses to concentrate on informatics and human-computer interaction and to make reference work and collection development elective courses, it is free to do so and will be accredited on that basis. To come to cases, a would-be doctor at an AMAaccredited medical school will take anatomy classes taught to national standards, whereas a would-be librarian at an ALA-accredited library school need not take courses in cataloguing and classification. It is hard to argue that knowledge of the latter is not as important to a librarian as anatomy is to a physician.

Diversity. The term diversity when used in the library education context usually refers to ethnic diversity. While it is true that ethnic minorities are under-represented in the ranks of graduates of LIS schools (though not among library workers in general), there are other aspects of diversity that must be considered. Librarians in the USA today are overwhelmingly female, middle class, white, and of a certain age. As my generation of librarians and the nearly as old generation are replaced in the coming decade or so, it is imperative that our profession (and the LIS schools that feed it) attract more younger and 
more culturally and ethnically diverse individuals. There are a number of programs to achieve this aim, notably ALA's Spectrum initiative, ${ }^{\text {vii }}$ but we need to do far more toward changing the perception of librarianship in the wider culture. Here again, I think we have taken the wrong turn. Trying to popularize libraries and librarianship by denying their essential nature has not worked and will not work. Advertising LIS schools as places to go if you do not want to work in libraries is not helpful to the cause either. It fools nobody to present libraries as if they were a species of computer arcade in which the core values of our profession—service, intellectual freedom, literacy and learning, preservation of the human record—are consigned to the dust-heap of history. We should be doing the opposite—celebrating our value and values, showing that computer technology is but a part of the wide and multidimensional range of programs and services that make up modern libraries, and presenting an optimistic energetic vision of our centrality to education, culture, and human progress. Given that vision of librarianship, I am confident that we could recruit would-be librarians in sufficient numbers and of a greater diversity. Twenty-first century library schools. I tend to believe in evolution not revolution in human affairs but am not sure that the former will get us to my vision of a library school of the $21^{\text {st }}$ century. I do believe we should try the evolutionary path but should be prepared for revolutionary change if that path 
proves unsatisfactory. Put simply, I would like library schools in the USA and elsewhere to:

- deliver a nationally agreed core curriculum to national standard levels have a core faculty (not including adjuncts) capable of teaching and doing research in all areas addressed by the core curriculum concentrate on teaching and research in librarianship teach and do research in other areas only when they have a satisfactory coverage of the core areas

be accredited in terms of national standards for function, structure, and performance

coöperate with library practitioners in all kinds of library to ensure coordination of library education in the schools and library training in the libraries and a smooth flow of new librarians from library schools to libraries.

Can we get there from here? Can library education and information science coexist in harmony without detriment to either or must they divorce? Can the American Library Association and the LIS schools work together to produce a national core curriculum? Can we revamp the accreditation system so that it is based on nationally agreed standards? Can we reconceptualize librarianship to make it attractive to future generations of librarians? I do not know the 
answer to any of these questions but I do know that, if we do not, at least, address them and, at best, answer them, the crisis in library education will become a catastrophe.

\section{Thank you.}

\section{Michael Gorman}

Dean of Library Services

California State University, Fresno

michaelg@,csufresno.edu

\footnotetext{
${ }^{\mathrm{i}}$ www.ala.org/library/fact1.html

ii . Houser, Lloyd. A conceptual analysis of information science. Library and information science research. 10 (January 1988) pp. 3-34.

iii Hildenbrand, Suzanne. The Information Age versus gender equity? Library trends, v.47,no.4 (Spring 1999), pp.669-685.

iv . Columbia University and the universities of Chicago and California, Berkeley are the most cited examples. v See: http://www.ala.org/Content/ContentGroups/HRDR/1st Congress on Professional Education/1st_Congre ss Appendix A ALA Core Values II Discussion Guide.htm and

http://www.ala.org/Content/ContentGroups/HRDR/1st Congress on Professional Education/1st Congre ss TF on Core Competencies Penultimate Report.htm

vi. http://www.ama-assn.org/ama/pub/category/2374.html

vii See

http://www.ala.org/Content/NavigationMenu/Our Association/Offices/Diversity3/Spectrum Initiative/Sp ectrum Initiative.htm
} 